\title{
A AVALIAÇÃO DAS APRENDIZAGENS NA FORMAC̣ÃO INICIAL DE PROFESSORES: DISCURSOS DE PROFESSORES/FORMADORES
}

\author{
Carlos Alberto Alves Soares Ferreira* \\ Universidade de Trás-os-Montes e Alto Douro (UTAD)
}

RESUMO: $\mathrm{Na}$ formação inicial de professores do $1^{\circ}$ ciclo do ensino básico, o ensino está centrado na aprendizagem e no trabalho autônomos dos futuros professores, e a avaliação das suas aprendizagens teve que se redirecionar nesse sentido. Assim, realizamos um estudo com docentes desses cursos, por meio de entrevistas nas quais afirmaram procurar avaliar os processos de realização de tarefas de aprendizagem dos futuros professores, na tentativa de diagnosticar atempadamente dificuldades e de os levar a ultrapassá-las. No entanto, consideraram que as práticas de avaliação formativa ainda não são as ideais, devido ao elevado número de alunos que cada docente tem, ao número e à diversidade de unidades curriculares que lecionam e, ainda, à falta de tempo para uma ajustada regulação do processo de ensino e de aprendizagem.

Palavras-chave: Formação de professores. Avaliação das aprendizagens. Discursos sobre as práticas avaliativas

\section{TEACHERS IN TRAINING LEARNING ASSESSMENT: TEACHERS / TRAINERS' DISCOURSES}

ABSTRACT: Concerning the 1st cycle of teachers-in-training basic education, the teaching is focused on learning and the future teachers' autonomous work. The evaluation of their learning had to be redirected accordingly. Thus, we conducted a study with teachers from these courses through interviews that affirmed that they seek to assess the implementation processes of the learning tasks of future teachers. There is an attempt to timely diagnose problems and bring the teachers to overcome them. However, they felt that formative assessment practices are still not ideal due to the high number of students that each teacher has, the number and diversity of courses they teach and also due to the lack of time for an adjusted regulation of the process of teaching and learning.

Keywords: Teachers training. Learning assessment. Discourses on assessment practices.

http://dx.doi.org/10.1590/0102-4698115623

"Doutor em Educação, na especialidade em Desenvolvimento Curricular. Professor da Universidade de Trás-os-Montes e Alto Douro e investigador do Centro de Investigação em Educação da Universidade do Minho (Portugal). E-mail: caferreira@utad.pt. 


\section{INTRODUÇÃO}

Vive-se no Ensino Superior português um momento de profundas mudanças pedagógicas, resultantes da adequação dos cursos ao processo de Bolonha ${ }^{1}$. No caso da formação inicial de professores do $1^{\circ}$ ciclo do ensino básico ${ }^{2}$, essas mudanças consubstanciam-se no ensino centrado nos estudantes, com a utilização de metodologias de ensino e de aprendizagem ativas e que tomem como objeto de estudo situações ou problemas reais de ensino nesse ciclo do ensino básico português. É com essas práticas pedagógicas que se torna possível aos futuros professores adquirir e/ou desenvolver competências profissionais e transversais necessárias ao exercício da profissão. Consequentemente, as práticas de avaliação das aprendizagens tiveram também que assumir uma vertente formativa e formadora da aprendizagem que os futuros professores irão realizar; têm que ser contínuas e centradas nos processos de aprendizagem, tomando como objeto os desempenhos ou os procedimentos a serem usados pelos futuros professores na realização de tarefas de aprendizagem.

Face a essas mudanças pedagógicas e avaliativas, foi nossa intenção ouvirmos docentes que formam futuros professores do $1^{\circ}$ ciclo do ensino básico português sobre as suas práticas de avaliação das aprendizagens, que é o que aqui pretendemos mostrar e sobre o que refletimos.

Assim, o presente texto inicia-se com a clarificação de alguns conceitos teóricos de avaliação das aprendizagens, passando, a seguir, para a reflexão teórica sobre as mudanças pedagógicas e nas práticas de avaliação das aprendizagens que o processo de Bolonha veio exigir aos docentes do Ensino Superior português, particularizando-se o caso da formação inicial de professores do $1^{\circ}$ ciclo do ensino básico. Depois, descrevemos o problema e os objetivos de investigação, bem como os procedimentos de recolha e de análise de dados. Por fim, apresentamos e refletimos sobre os discursos dos formadores de professores do $1^{\circ}$ ciclo do ensino básico da Universidade de Trás-os-Montes e Alto Douro em relação às suas práticas de avaliação das aprendizagens e aos obstáculos por eles sentidos para a realização de uma avaliação formativa e formadora.

\section{A AVALIAÇÃO DAS APRENDIZAGENS: CONCEITOS ORIENTADORES}

Apesar de o termo "avaliação" ser polissêmico, dado ser aplicado em diferentes contextos e utilizado com diversas finalidades, já desde fins da década de 1960 que se entende a avaliação das 
aprendizagens como um processo planificado e estruturado de recolha e de análise de informações sobre as aprendizagens dos alunos, a partir do qual é formado um juízo de valor conducente à tomada de decisões diferentes consoante a finalidade e a função da avaliação em causa (FERREIRA, 2007).

Essa concepção de avaliação remete-nos para uma prática avaliativa estruturada por etapas sequenciais (ROSALES, 1992). Depois de planificada a prática de avaliação das aprendizagens, tendose em conta a finalidade e aquilo que se toma por objeto de avaliação, procede-se à recolha de informações sobre as aprendizagens dos alunos. Essa recolha é feita com base na utilização de procedimentos técnicos e de instrumentos de avaliação, e as informações por meio deles obtidas são analisadas pela comparação com um referente, delimitado por critérios ou por normas que indicam o ideal de resposta ou de comportamento do aluno (ALVES, 2004; FIGARI, 1996; HADJI, 2001). Dessa comparação, que permite verificar o grau de proximidade do aluno relativamente aos critérios de avaliação ou normas, resulta um juízo de valor. Esse juízo de valor exprime-se de forma descritiva, em caso de identificação dos pré-requisitos ou dos conhecimentos prévios dos alunos e das aprendizagens já feitas e das suas dificuldades, ou de forma quantitativa, pela atribuição de uma nota ao resultado de aprendizagem numa escala formalmente adotada. Ele possibilita a tomada de decisões para o processo de ensino e de aprendizagem, ou a certificação, ou não, das aprendizagens realizadas (ALVES, 2004; FERREIRA, 2007).

Entendendo-se que a avaliação da aprendizagem pode ser feita com diferentes finalidades e para serem tomadas decisões também diversas, é comum verificarem-se nas práticas avaliativas em contextos escolares a avaliação diagnóstica, a formativa e a sumativa. A avaliação diagnóstica corresponde àquela efetuada no início do processo de ensino e de aprendizagem (no início do ano letivo, de uma unidade de conteúdos ou de uma aula) para verificar se os alunos possuem os pré-requisitos necessários às novas aprendizagens a fazer, ou para diagnosticar os conhecimentos prévios sobre um dado assunto a ensinar, ou, ainda, para verificar os interesses dos alunos relativamente a um tema que vai ser objeto de ensino e de aprendizagem (CORTESÃO, 2002; FERREIRA, 2007; LEITE; FERNANDES, 2002). São recolhidas essas informações para o professor, com ou sem a participação dos alunos, tomar decisões sobre os conteúdos a ensinar e a sequência a dar-lhes, sobre os objetivos que os alunos poderão cumprir num dado período 
de tempo de ensino e de aprendizagem e sobre as estratégias e as atividades adequadas ao ponto de partida dos alunos e aos conteúdos selecionados (FERREIRA, 2007).

Se a avaliação diagnóstica permite verificar o ponto de partida dos alunos na aprendizagem, devendo, por isso, ser considerada inicial e momentânea (CORTESÃO, 2002), é necessário avaliar continuamente as aprendizagens que os alunos estão a fazer, no sentido de se verificar se estão a caminhar para o cumprimento dos objetivos delineados ou se têm dificuldades que precisam superar. Só assim é possível ao professor e ao aluno tomar consciência, em tempo útil, do processo de aprendizagem que está a ser efetuado e, em caso de dificuldades ou de erros, poder intervir atempadamente, de forma a obterem sucesso escolar na avaliação final ou sumativa (FERREIRA, 2007; LEITE; FERNANDES, 2002). Daí a importância da prática da avaliação formativa, que pode ser realizada pelo professor, ou pelo professor com cada aluno, ou, ainda, pelo próprio aluno autonomamente, por meio da sua autoavaliação (BÉLAIR, 2000). Para isso, têm de estar devidamente clarificados os critérios de avaliação das tarefas de aprendizagem (de realização e de sucesso), de modo que os alunos possam refletir e consciencializar-se das aprendizagens que estão a conseguir fazer e das dificuldades que têm, ou dos erros cometidos (BÉLAIR, 2000; HADJI, 2001; LEITE; FERNANDES, 2002). A intervenção neles é feita pela adaptação das estratégias, das atividades e dos recursos de ensino e de aprendizagem, o que permite criar as condições pedagógicas necessárias para que cada aluno com dificuldades as possa vencer. Por este motivo, Perrenoud (1993) afirma que a avaliação formativa constitui uma prática que ajuda o professor a ensinar e o aluno a aprender, assumindo uma dimensão formadora para ambos (ALVES, 2004). Isso porque a prática da avaliação formativa leva o professor a refletir continuamente sobre a sua ação didática, no sentido de a adequar aos diferentes percursos de aprendizagem dos alunos. Também leva os alunos a consciencializaremse dos seus processos de aprendizagem e a encontrarem, com ou sem o professor, os meios necessários para ultrapassarem as dificuldades, ou para corrigirem os erros (HADJI, 2001; LEITE; FERNANDES, 2002), numa perspetiva de ensino individualizado.

No contexto das políticas educativas atuais, a prestação de contas por parte dos professores e das escolas pelo serviço educativo realizado é uma realidade (AFONSO, 2011; PACHECO, 2011). Essa prestação de contas tem vindo a ser feita pelos resultados escolares dos alunos, de modo que, com base deles, comprova-se à sociedade que 
os alunos cumpriram as normas de excelência exigidas pelos grupos sociais e economicamente dominantes e que estão bem presentes no currículo escolar (PERRENOUD, 1998). Daí que os professores são confrontados com a obrigatoriedade de medir e de classificar os resultados de aprendizagem dos seus alunos. Tal medição ocorre no fim do processo de ensino e de aprendizagem (período ou ano letivo) e é feita, normalmente, por meio de testes e de exames escritos. Concebidos em função dos conteúdos programáticos ensinados e das metas de aprendizagem estabelecidas no currículo formal, esses instrumentos permitem situar os alunos num determinado ponto de uma escala de classificação formalmente adotada, em função do maior ou do menor grau de proximidade do desempenho dos alunos nesses testes e exames às metas estabelecidas ou aos critérios normativos. Dessa forma é cumprida a função sumativa da avaliação da aprendizagem, da qual resultam decisões de hierarquização dos alunos numa escala formalmente adotada, de aprovação ou de reprovação, de certificação, ou não, das suas aprendizagens.

\section{CONTEXTO DE AVALIAC̣ÃO DAS APRENDIZAGENS NO ENSINO SUPERIOR PORTUGUÊS}

O Ensino Superior português, da mesma forma que o de outros países da União Europeia, sofreu alterações resultantes da assinatura da Declaração de Bolonha, em 1999, contextualizada na procura da criação de um espaço europeu de Ensino Superior e da Europa do conhecimento (PACHECO, 2011). Essas alterações fizeram-se sentir na organização, na estrutura e nas práticas de ensino, de aprendizagem e de avaliação dos estudantes no Ensino Superior português.

2.1 ENSINO SUPERIOR: NOVO CONTEXTO, NOVAS PRÁTICAS PEDAGÓGICAS, NOVAS APRENDIZAGENS DOS ESTUDANTES

Decorrente de uma agenda globalmente estruturada em função dos interesses econômicos e financeiros numa sociedade globalizada (LIMA; AZEVEDO; CATANI, 2008, a Declaração de Bolonha (1999) trouxe mudanças organizacionais e pedagógicas no Ensino Superior nos diversos países que a subscreveram (PACHECO, 2003). Para além da compatibilização dos graus acadêmicos, essas mudanças consistiram na formação dos alunos por unidades de crédito, no incremento da mobilidade dos estudantes, de professores e investigadores pelos diversos países europeus, na organização do processo pedagógico por horas de contato, de tutoria e por tempo de estudo e de trabalho 
autônomos dos estudantes (DECLARAÇÃO DE BOLONHA, 1999; LIMA; AZEVEDO; CATANI, 2008; SIMÃO; SANTOS; COSTA, 2005). Todas essas mudanças foram justificadas pela necessidade de criar uma Europa do conhecimento, capaz de competir internacionalmente, com inovação, com coesão social e com profissionais altamente qualificados, com vista ao seu desenvolvimento econômico e social (PASTOR, 2011; SIMÃO; SANTOS; COSTA, 2005).

É no contexto da sociedade do conhecimento, de competitividade econômica e de necessidade de qualificação da mão de obra que a aprendizagem ao longo da vida de conhecimentos diversos e de saberes procedimentais e atitudinais é um requisito essencial para a integração ativa dos cidadãos (LIMA; AZEVEDO; CATANI, 2008 PASTOR, 2011; PACHECO, 2011). Logo, é preciso que as instituições formativas, nas quais se incluem as universidades, possibilitem aos estudantes a aprendizagem de conhecimentos e de competências específicas da área de formação, mas também de competências transversais (tomada de decisões em função de situações e problemas concretos, criatividade, inovação, cooperação etc.) necessárias ao mercado de trabalho e à vida numa sociedade regulada pela economia (MORGADO, 2009; SECO et al., 2011). Como refere Santamaria (2011, p. 41), "as exigências didáticas, curriculares e de avaliação geradas no marco do desenvolvimento do espaço europeu de educação superior vêm configuradas pela emergência do enfoque de competências". Isso porque é necessário que os estudantes aprendam conhecimentos teóricos e técnicas na área específica da sua formação, mas também que adquiram atitudes e procedimentos que possibilitam mobilizar, de forma adequada e eficaz, esses conhecimentos e procedimentos para a resolução de problemas profissionais e sociais. Nesse sentido, Valverde, Revuelta e Fernandéz (2012, p. 53) afirmam que "a competência é de origem profissional e está vinculada à ideia de realizações na "vida real"'. $\mathrm{E}$ acrescentam que, por essa razão, as competências

são compostas por um conjunto de estruturas de conhecimento, assim
como de habilidades cognitivas, interativas e afetivas, atitudes e valores, que
são necessárias para a execução de tarefas, a solução de problemas e um
desempenho eficaz numa determinada profissão, organização, posição ou
papel. (VALVERDE; REVUELTA; FERNÁNDEZ, 2012, p. 53)

Uma vez que são as instituições de Ensino Superior que criam, privilegiadamente, as condições de "fabricação cognitiva de saberes relacionados com contextos específicos da economia" (PACHECO, 2011, p. 19), é a elas que cabe o papel de promover a aprendizagem 
daqueles conhecimentos e das referidas competências, com a participação ativa dos estudantes na construção dessas aprendizagens. Daí que essa aquisição de conhecimentos e de competências tem que ser feita por meio da aprendizagem e do trabalho autônomos dos estudantes, tal como previsto pela Declaração de Bolonha (1999). Por essa razão, afigura-se como oportuna ao processo de aprendizagem a utilização, por parte dos professores do Ensino Superior, de metodologias de ensino ativas para os alunos, tais como o trabalho de projeto, os debates sobre temas da realidade profissional, os fóruns de debate, a pesquisa de temas do interesse dos alunos, o trabalho de campo etc., de modo que os estudantes façam aprendizagens úteis e com sentido (MORGADO, 2009 FERREIRA, 2011).

Essa aprendizagem só é conseguida se for realizada pelo confronto com situações ou problemas reais relacionados com os futuros contextos profissionais. Tal é proposto por Morgado (2009, p. 55) quando refere que

no plano do ensino-aprendizagem, é imperioso que o núcleo enfático se desloque do ensino para a aprendizagem e que a produção de conhecimento vise, sobretudo, as suas aplicações a situações reais do quotidiano, deixando de prevalecer a construção/transmissão do conhecimento pelo conhecimento.

Em todo esse processo pedagógico, o papel dos professores muda, já que passam a ser facilitadores, orientadores e mediadores da aprendizagem dos estudantes (ESTEVES, 2008). Ou seja, os professores têm que criar oportunidades de aprendizagem para os estudantes por meio de um ensino baseado em situações ou problemas da realidade profissional para a qual estão a ser formados. Para isso, têm de disponibilizar ou de indicar os recursos necessários à construção das aprendizagens pelos alunos, orientando-os nos processos de pesquisa sobre essas situações ou problemas da vida profissional, esclarecendo-lhes dúvidas, dando-lhes indicações para a melhoria ou para o aprofundamento dos temas ou dos assuntos que estão a ser tratados, ou até dos próprios processos de pesquisa por eles desenvolvidos (LEBRUN, 2008). Desse modo, o professor permite que os alunos realizem uma aprendizagem com sentido e útil para a sua formação profissional, mas também pessoal.

Todas essas exigências com que o Ensino Superior se depara também se fazem sentir na formação inicial de professores. Estando, atualmente, os professores confrontados com problemas e necessidades diferentes daquelas que se faziam sentir há uns anos, resultantes da massificação da educação escolar e das influências da sociedade da informação e da comunicação nos alunos que 
frequentam as escolas (ROLDÃO, 2002), o seu papel teve que mudar. Logo, a formação de professores, quer inicial, quer contínua, tem que se ajustar a esta nova realidade profissional. Daí que os futuros professores não podem encarar a formação inicial como aquela que os prepara para o exercício de funções profissionais para toda a vida (ROLDÃO, 2002). Por outro lado, também não basta formar professores com conhecimentos científicos e pedagógicos e com algumas técnicas de ensino; ainda é fundamental que, para além desses conhecimentos, os futuros professores adquiram competências curriculares, pedagógico-didáticas, organizacionais, éticas, de reflexão e de pensamento crítico, comunicacionais e relacionais, de cooperação e de tomada de decisões em função de situações ou problemas educativos concretos (ALONSO, 2005; PERRENOUD, 2000), servindo essas de base para uma aprendizagem ao longo da vida, proporcionada por um processo contínuo de formação.

\subsection{A AVALIAC̣ÃO DAS APRENDIZAGENS NO CONTEXTO DA FORMAC̣ÃO INICIAL DE PROFESSORES}

Se, por um lado, a realidade profissional com que os futuros professores se irão deparar lhes obriga a fazer aprendizagens de conhecimentos e de competências diversificados que lhes permitam dar respostas adequadas às exigências dessa realidade, por outro lado, o processo de Bolonha conduz a que essas aprendizagens sejam feitas pelos estudantes de forma autônoma, embora supervisionada e orientada pelos seus professores. Tais fatos pressupõem uma nova concepção e uma nova prática de avaliação das aprendizagens na formação inicial de professores, isso porque a avaliação das aprendizagens não pode centrar-se exclusivamente nos resultados do domínio cognitivo (conhecimentos e capacidades cognitivas básicas) e ser realizada unicamente por testes e exames escritos (FERNANDES, 2010; PASTOR, 2011).

Face a um novo objeto de aprendizagem, dominado pela aquisição de competências profissionais, pessoais e sociais, é preciso criar novas situações de aprendizagem para os estudantes, nas quais lhes seja possível mobilizar, de forma integrada, recursos cognitivos, atitudinais e procedimentais (PACHECO, 2011; SANTAMARIA, 2011), mobilização esta passível de ser avaliada de forma contínua por meio de diversificadas técnicas e instrumentos de avaliação adequados aos diferentes objetos avaliativos, mas que incidam sobre a transferibilidade do conhecimento (FERNANDES, 2010; PACHECO, 2011; PASTOR, 2011). Desse modo, Valverde, Revuelta e Fernandéz (2012) afirmam que a avaliação de competências tem que constituir 
um processo de recolha de evidências, com base na realização de atividades de aprendizagem pelos estudantes, e de formulação de valorações sobre a natureza do progresso desses estudantes, segundo resultados de aprendizagem esperados e do seu conhecimento. Também a esse propósito, Santamaria (2011, p. 42) refere que, sendo o estudante protagonista do seu processo de aprendizagem, de conhecimentos e de competências, "avaliar competências pressupõe a implicação pessoal de cada estudante, que se envolva em cada atividade proposta, que faça reflexão intelectual em cada tarefa e realize a sua própria valoração da aprendizagem que vai realizando". Ou seja, é fundamental a prática da avaliação formativa e da autoavaliação do seu processo de aprendizagem pelo futuro professor.

Uma vez que as competências profissionais, pessoais e sociais são adquiridas ou ampliadas por meio da busca de respostas para reais situações educativas complexas ou problemáticas, os futuros professores têm que analisar e refletir sobre essas situações e mobilizar os recursos necessários para intervirem nelas de forma adequada e eficaz. Daí que a avaliação tenha de incidir no processo de análise e de intervenção nas situações da realidade educativa propostas no contex to de ensino e de aprendizagem e ser orientada por um referente delimitado por critérios de avaliação das tarefas de aprendizagem que sejam claros e do conhecimento dos dois intervenientes (ALLAL, 1999; HADJI, 2001). Como nos dizem Clares, Juárez e Cantero (2008, p. 207), "avaliar as competências requer e exige critérios, fontes e processos adaptados a cada atividade".

Sendo planificada e orientada por um referente delimitado e compreendido (FIGARI, 1996), essa prática da avaliação formativa contínua tem de ser concretizada, sobretudo, pela observação sistemática dos estudantes no processo de aprendizagem e pela autoavaliação do estudante. Isso permite ao professor e ao estudante diagnosticar, em tempo útil, as aprendizagens feitas e as suas dificuldades. No entanto, também instrumentos como portfólios, ensaios, trabalhos escritos, pôsteres, simulações etc., usados com regularidade, são passíveis de possibilitar informações atempadas sobre as aprendizagens e sobre as dificuldades que os estudantes estão a sentir, ou sobre aspetos que precisam ser melhorados (PASTOR, 2011). A partir da recolha e da análise contínuas das informações sobre o modo como os alunos resolvem as situações de ensino em que se encontram envolvidos, pela sua comparação com os critérios de avaliação definidos, o professor e cada aluno tomam consciência dos erros cometidos, das dificuldades sentidas ou dos aspetos a melhorar (FERREIRA, 2007). Com o feedback que vai sendo proporcionado 
(FERREIRA, 2011), criam-se as condições para que, com o professor ou de forma autônoma pelo estudante (autorregulação), sejam utilizadas estratégias que possibilitem ultrapassar dificuldades e erros, ou melhorar o que tem que ser melhorado na aprendizagem. Dessa forma é possível que os futuros professores tenham sucesso na avaliação sumativa e sejam competentes profissionalmente.

\section{METODOLOGIA DE INVESTIGAC̣ÃO}

A Declaração de Bolonha (1999) veio exigir profundas mudanças pedagógicas e nas práticas avaliativas no Ensino Superior dos diversos países europeus que a assinaram. Foi nesse contexto que decidimos iniciar um estudo, que se encontra em desenvolvimento, sobre os discursos de professores da Universidade de Trás-os-Montes e Alto Douro (UTAD, Portugal) sobre as suas práticas de avaliação das aprendizagens no âmbito das unidades curriculares que lecionavam nos três mestrados que formam futuros professores do $1^{\circ}$ Ciclo do Ensino Básico português (Mestrado em Educação Pré-Escolar e Ensino no $1^{\circ}$ Ciclo do Ensino Básico; Mestrado em Ensino no $1^{\circ}$ Ciclo do Ensino Básico; Mestrado em Ensino no $1^{\circ}$ e no $2^{\circ}$ Ciclos do Ensino Básico). Daí que o problema que orientou esta investigação apresentou-se o seguinte: quais os discursos de professores da Universidade de Trás-os-Montes e Alto Douro (UTAD) que formam futuros professores do $1^{\circ}$ ciclo do ensino básico sobre as suas práticas de avaliação no âmbito da(s) unidade(s) curricular(es) que lecionam?

Tendo em atenção o problema de investigação apresentado, delineamos como objetivos da investigação os seguintes:

- Compreender a concepção de avaliação das aprendizagens de docentes envolvidos na formação inicial de professores do $1^{\circ}$ ciclo do ensino básico da UTTAD;

- Caraterizar as práticas de avaliação das aprendizagens realizadas pelos docentes participantes no estudo a partir dos seus discursos sobre as mesmas;

- Verificar, a partir dos discursos dos professores, o papel dos futuros professores no processo de avaliação das próprias aprendizagens;

- Identificar os obstáculos apontados pelos docentes à realização das práticas de avaliação das aprendizagens. 
Para darmos resposta ao problema identificado e, dessa forma, cumprirmos os objetivos a que nos propusemos com a investigação, pareceu-nos adequada a opção por uma metodologia de investigação qualitativa (BOGDAN; BIKLEN, 1994), concretizada pela realização de entrevistas semiestruturadas com docentes que formam futuros professores do $1^{\circ}$ ciclo do ensino básico e que, por isso, lecionam unidades curriculares nos mestrados atrás mencionados. Para isso, foi construído um guia de entrevista, com questões relativamente abertas, que foi analisado por dois professores que não participaram no estudo, com vista a opinarem sobre a adequação e a clareza das questões, a sua abrangência relativamente aos assuntos a abordar e a necessidade ou não de retirar ou de acrescentar questões (GHIGLIONE; MATALON, 1992). Nessa análise prévia do guia da entrevista por esses professores, não foi verificada a necessidade de proceder a quaisquer alterações, pelo que decidimos utilizá-lo na condução das entrevistas.

Até ao momento, foram realizadas entrevistas com quatro docentes dos mestrados de formação de futuros professores do $1^{\circ}$ ciclo do ensino básico da UTAD, que tinham experiência docente de 20 a 26 anos na formação daqueles professores. Antes da realização das entrevistas, esses professores foram previamente informados dos objetivos da investigação e, mais especificamente, da entrevista e foi-lhes solicitada autorização para a gravação de áudio das mesmas. Ainda lhes foram garantidos, como sugerem os princípios éticos da investigação qualitativa (BOGDAN; BIKLEN, 1994; LIMA, 2006), o anonimato e a confidencialidade dos dados fornecidos. Essas entrevistas foram realizadas nos meses de outubro e novembro de 2012, nos gabinetes dos próprios docentes.

Para a análise dos quatro protocolos das entrevistas, começamos por transcrever os discursos dos professores, procurando ser o mais fiéis possível às suas verbalizações. Em seguida, procedemos à análise de conteúdo das transcrições efetuadas, com vista a organizarmos e darmos significado aos dados recolhidos, bem como a podermos fazer inferências (BARDIN, 1995; ESTEVES, 2006). Essa análise foi iniciada por uma primeira leitura flutuante (BARDIN, 1995) dos discursos dos professores, e, seguidamente, foram feitas outras leituras para delimitarmos as categorias e as subcategorias encontradas. Foi, desse modo, realizada uma categorização emergente (BARDIN, 1995; ESTEVES, 2006), da qual resultaram as seguintes categorias e subcategorias: 1 . Conceito de avaliação das aprendizagens; 2. O referente da avaliação das aprendizagens; 3 . Avaliação diagnóstica; 4. Procedimentos da prática da avaliação formativa, com as seguintes subcategorias: a) objeto de avaliação formativa; b) técnicas e 
instrumentos de avaliação formativa; c) prática da autoavaliação do aluno; 5. A regulação da aprendizagem, com as seguintes subcategorias: a) feedback; b) revisão de conteúdos pelo professor; c) a ajuda de colegas; 6. Obstáculos à prática da avaliação formativa; 7. Procedimentos da prática da avaliação sumativa, com as seguintes subcategorias: a) técnicas e instrumentos de avaliação sumativa; b) ponderação dos instrumentos de avaliação na classificação final; 8 . Aspectos a melhorar na prática avaliativa.

\section{AS PRÁTICAS AVALIATIVAS NA FORMAC̣̃̃O DE PROFESSORES DO $1^{\circ}$ CICLO DO ENSINO BÁSICO NA VOZ DOS PROFESSORES FORMADORES}

Tendo procurado aceder aos discursos de quatro docentes formadores de professores do $1^{\circ}$ ciclo do ensino básico sobre as suas práticas avaliativas, apresentamos e refletimos em seguida os resultados obtidos, de acordo com as categorias e as subcategorias que emergiram da análise de conteúdo realizada com os protocolos das entrevistas feitas.

Tendo procurado auscultar os professores formadores sobre o seu entendimento do que é a avaliação das aprendizagens, pudemos verificar que não a associam unicamente aos procedimentos de avaliação sumativa, como tradicionalmente tem sido entendida (FERNANDES, 2010; PACHECO, 2011). Para eles, avaliar é, também, acompanhar os percursos de aprendizagem dos futuros professores do $1^{\circ}$ ciclo do ensino básico português e ajudá-los a ultrapassar dificuldades, regulando a sua aprendizagem. Procurando ajustar o entendimento da avaliação das aprendizagens às orientações de Bolonha, o conceito de avaliação evidenciado pelos professores já não contempla só a medição de resultados de aprendizagem e a classificação dos alunos no fim da unidade curricular, mas também inclui uma dimensão formativa, que se traduz pelo acompanhamento dos alunos no processo de aprendizagem e, por isso, pela recolha e pela análise contínuas de informações com vista à regulação desse processo (FERREIRA, 2007; VALVERDE; REVUELTA; FERNÁNDEZ, 2012):

De acordo com os objetivos dos cursos, temos agora uma avaliação contínua e, nesta perspetiva, eu não posso descuidar o caráter muito formativo desta avaliação. (Professor A)

Avaliar é perceber que tipo de evolução é que os alunos tiveram, tendo em conta o estado de conhecimentos que eles tinham e os objetivos que eu achei que era possivel ter para aquela unidade curricular. (Professor B)

Como em qualquer outro nivel de ensino, avaliação é sempre a emissão de um juízo de valor sobre alguma coisa, não é? É a classificação. Na avaliação sumativa é a classificação e a seriação dos alunos. Isso é sempre o ponto final da avaliação. Mas também é, sem dúvida, a avaliação formativa e a recolha de informacõoes, no sentido de ajustar a prática com 0 
acompanhamento que faço dos alunos para uma aprendizagem mais eficazporparte destes. É sempre a regulação do processo de ensino e de aprendizagem. (Professor C)

Avaliar os alunos é procurar acompanhá-los durante a aprendizagem para ver as suas dificuldades e tentar solucioná-las, mas também é, como temos que fazer, classificar os alunos e aprová-los on reprová-los. (Professor D)

Congruente com essa concepção de avaliação das aprendizagens, as práticas avaliativas que os docentes disseram realizar contemplam não só a dimensão sumativa, exigida formalmente pelas instituições de ensino e pela sociedade em geral(FERNANDES, 2010; PERRENOUD, 1998), como a formativa. Tais práticas são realizadas com um referente (FIGARI, 1996; ALVES, 2004), descrito em objetivos de aprendizagem e em critérios de avaliação para as diferentes tarefas de aprendizagem e de avaliação de cada unidade curricular em causa:

\footnotetext{
Há anos em que eu apresento os objetivos da unidade curricular, clarifico os objetivos para uma sequência de aulas, em que eles sabem bem o que eu pretendo com as aprendizagens. [...] Se tenho o trabalho de grupo com $25 \%$, eu tenho os critérios de avaliação para a parte escrita e eles sabem. Por exemplo, eu vejo a clareza com que eles se exprimem, o aprofundamento, e tudo isso é esmiuçado. Eles sabem os critérios todos, para a parte escrita, para a parte oral. (Professor A)

Ter sempre a preocupação de definir os trabalhos que eles têm que faz̧er, de apresentar sempre os critérios de avaliação para esses trabalhos. Eles têm sempre o conbecimento desses critérios de avaliação, no sentido de saberem o que é esperado quando faz̧em o trabalho. (Professor C)

A minha avaliação é composta por vários trabalhos que eles têm que faz̧er e, para cada trabalho, dou os critérios de avaliação logo no início do trabalho, para que os alunos saibam o que têm que fazer, para poderem ser bem-sucedidos nos trabalhos. (Professor D)
}

Procurando clarificar o referente da avaliação para eles e para os estudantes, os professores formadores contemplam em suas práticas as várias funções pedagógicas tradicionais da avaliação das aprendizagens: a diagnóstica, a formativa e a sumativa (FERREIRA, 2007; HADJI, 2001). Assim, dois professores entrevistados referiram fazer sempre a avaliação diagnóstica, sendo esta realizada, no caso de um deles, na primeira aula da unidade curricular e, para o outro docente, no início de cada aula. A avaliação diagnóstica é feita para verificarem os pré-requisitos e os conhecimentos prévios dos alunos sobre os conteúdos a trabalhar (FERREIRA, 2007; LEITE; FERNANDES, 2002). A sua prática é concretizada, segundo eles, pelo diálogo com os alunos, para tomarem decisões sobre por onde começar e como ensinar os conteúdos e para selecionarem os objetivos de aprendizagem que terão que cumprir na unidade curricular e até em cada aula (FERREIRA, 2007; CORTESÃO, 2002): 
Eu tenho os objetivos à partida. A partir da primeira aula, eu tento ver se esses objetivos são atingíveis ou não, de acordo com uma breve avaliação diagnóstica que faço [...] oralmente, conversando com eles na primeira aula. Depois, tento encontrar um balanço entre aquilo que eles têm, aquilo que eles são e aquilo que eu gostaria que eles aprendessem com a minha unidade curricular. (Professor B)

Eu informo sempre, na primeira aula, os objetivos que os alunos têm que cumprir na unidade curricular e em cada aula eu começo questionando oralmente os alunos sobre o que sabem, se é que sabem alguma coisa, sobre o assunto que vou trabalhar na aula. Começo sempre o trabalho dos conteúdos a partir daquilo que eles me dizem sobre esse assunto da aula. (Professor D)

Essa prática da avaliação diagnóstica possibilita aos professores tomar decisões para o processo de ensino e aprendizagem nas suas unidades curriculares, selecionando os objetivos mais adequados ao ponto de partida dos alunos e os conteúdos a ensinar, tal como é sugerido por Cortesão (2002) e por Ferreira (2007).

Para além da avaliação diagnóstica, os professores verbalizaram a tentativa que fazem de realizar uma prática de avaliação formativa, centrando-se esta na observação e no acompanhamento dos alunos durante as tarefas de aprendizagem e de avaliação e ainda na correção dos trabalhos feitos, com o respetivo feedback aos alunos, que lhes possibilita consciencializar-se do que fizeram bem e das suas dificuldades ou erros, tal como sugere Hadji (2001), Fernandes (2010) e Ferreira (2011). Essas tarefas de aprendizagem -elaboração de planos de aulas, projetos de investigação em educação, utilização de métodos de aprendizagem cooperativa em situações simuladas, utilização da metodologia de trabalho de projeto em turmas do $1^{\circ}$ ciclo do ensino básico etc. - baseiam-se em situações ou funções de ensino, levando os futuros professores a mobilizarem, em cooperação, diversos tipos de conhecimentos e de procedimentos que estão a aprender; dessa forma, adquirirem competências profissionais (ALONSO, 2005). A partir das informações recolhidas e analisadas pela comparação com os critérios de avaliação predeterminados é construído um juízo de valor sobre as aprendizagens que estão a fazer e é realizado o diagnóstico das dificuldades dos futuros professores, de modo a se proceder a algum tipo de regulação do seu processo de aprendizagem (CORTESÃO, 2002; FERREIRA, 2007; HADJI, 2001):

A avaliação tem que ser constante para eu remediar imediatamente as dificuldades. Remediar as dificuldades é a minha concep̧̣ão básica. Eu considero que é o mais importante. (Professor A)

Sempre preferi aulas de três horas, em que faço uma primeira parte da aula teórica, faço intervalo e depois a parte prática, em que eles estão a fažer o trabalho de grupo, para 
além de uma parte individual. Mas eu vou acompanhando esse trabalho nas aulas. [...] Normalmente, eu peço-lhes o indice provisório do trabalho e eu corrijo esse indice, para não fazerem uma coisa errada. Depois, quando começam a construir o trabalho e a escrever, eu comeco-lhes a corrigir a escrita, ainda sem ir ao conteúdo. Depois, a um nivel mais aprofundado, é que vou ao conteúdo. (Professor B)

Nas planificações, primeiro é dada a estrutura e os critérios para a avaliação da planificação, depois eles organiżam a primeira planificação com o meu acompanhamento. Mas depois finalizam sozinhos, porque são muitos grupos. Depois vão entregar a planificação, eu vou pegar nela, vou ter um tempo próprio para corrigir. Gosto de fazer isso sossegada, vendo tudo, analisando ao pormenor e com muito cuidado essa planificação e depois é dado feedback aos alunos. (Professor C)

Eu corrijo os trabalhos dos alunos com base nos critérios de avaliação que eles conbecem e para cada trabalho preencho uma folh a com os critérios e faço um comentário escrito para cada critério. Depois, levo os trabalhos para a aula, para os alunos verem o trabalho corrigido e os meus comentários escritos para cada critério de avaliação. (Professor D)

Os docentes entrevistados verbalizaram tentar realizar essa prática da avaliação formativa com o recurso a diferentes técnicas e instrumentos de avaliação, resultantes das opções ideológicas sobre educação e sobre a avaliação da aprendizagem de cada um, do objeto de avaliação e da finalidade da mesma (FERREIRA, 2007; HADJI, 2001). Assim, o professor A disse utilizar o que designou de "bilhete à saída", que consiste num registro escrito feito pelos alunos em casa sobre as dificuldades que tiveram nas aulas, ou sobre aquilo que não compreenderam e que entregam ao professor, de maneira que sejam esclarecidas as dificuldades nas aulas seguintes:

\footnotetext{
Mas como eu gosto que eles apliquem diferentes técnicas de avaliação formativa aos alunos, utilizo o bilhete à saída. Por exemplo, vamos ver se eles deixam um cartão no final da aula com aquilo que para eles ficou duvidoso, no sentido de eles ponderarem, como trabalbo de casa, o que não perceberam e é por aí que eu começo as aulas seguintes. Eu recolho esses cartões com as dúvidas. [...] Hoje, por exemplo, eu comecei a aula pedindo aos alunos para colocarem o bilhete em cima das mesas e eu comecei a aula por aí. (Professor A)
}

Esse professor ainda referiu o questionamento oral feito pelos alunos sobre os conteúdos que estavam a ser ensinados como forma de verificar as dificuldades que sentiam, para que ele as pudesse resolver:

Eu também os treino a fazer perguntas. Eles próprios podem fazer perguntas sobre a matéria. Por exemplo, um aluno colocou uma pergunta que era qual a diferença entre meta e objetivo de aprendizagem e depois en clarifiquei. (Professor A)

O professor B mencionou realizar práticas de avaliação formativa sobretudo nas aulas práticas, quando os futuros professores, em pequenos grupos, realizam um trabalho de concepção de um projeto de investigação sobre um problema do domínio da educação 
para a sua avaliação na unidade curricular e que é acompanhado pelo professor. Durante esse trabalho, o professor vai circulando pelos grupos, observando o que estão a fazer, registrando numa grelha de observação as aprendizagens e as dificuldades sentidas, bem como a sua participação nesse trabalho, de modo a essas informações não ficarem esquecidas, tal como sugere Hadji (2001) e Cortesão (2002). Quando detecta alguma dificuldade, esclarece-a ao grupo, ou mesmo à turma toda, caso se justifique:

É uma grelha de procedimento que fir há muitos anos. [...] Então, ponho no cimo o trabalho [o tema/problema de investigação que cada grupo escolheu], ponho a unidade curricular, o curso, turma 1 ou 2, porque são várias turmas, e depois eles formam os grupos e põem aqui os nomes. [...] Depois, eu fui grupo a grupo e fui tomando nota aqui se estão a participar, se não estão, se estão a trabalhar bem ou não. (Professor B)

O professor C, sendo o responsável pela supervisão dos estágios de fim de curso, referiu as reuniões de reflexão sobre as aulas lecionadas pelos futuros professores, das quais participam os estagiários, a supervisora da universidade e o professor orientador da escola, como momentos privilegiados de diagnóstico dos aspetos que correram bem e das dificuldades na prática de ensino dos futuros professores. Todo esse diagnóstico é feito a partir de critérios de avaliação da prática de ensino dos futuros professores em sala de aula e que são do conhecimento dos diversos intervenientes, de modo que cada estagiário, nas aulas seguintes de sua responsabilização, possa superar as dificuldades sentidas e que foram refletidas nessas reuniões:

Faz̨em-se reuniões periódicas, não é? São semanais com a professora [da escola], quinzenais comigo, por uma questão de tempo. Dois alunos dão aula, reunimos, falamos nas dificuldades, sempre com base nos instrumentos que suportam a nossa análise. [...] Depois tentamos, na semana seguinte, que esses aspectos sejam alterados e, normalmente, o sucesso no desempenho do estágio tem a ver com isso. A forma como eles vão integrando os comentários que vamos fazendo, as chamadas de atenção que fomos fazendo, vão alterando e melhorando. (Professor C)

Alguns professores verbalizaram a realização de práticas de autoavaliação dos futuros professores no contexto da avaliação formativa, apesar de não serem sistemáticas nem muito estruturadas. Essa autoavaliação, fundamental para a reflexão e para a tomada de consciência do estudante sobre a sua aprendizagem (ALLAL, 1999; BÉLAIR, 2000; LEITE; FERNANDES, 2002), é feita, no âmbito da unidade curricular do professor $\mathrm{A}$, mediante a reflexão dos estagiários sobre o cumprimento de objetivos de uma sequência de aulas e o respectivo registro numa ficha onde constam esses objetivos: 
Depois de ensinar determinados conteúdos que eu considero importantes, ao fim desses conteúdos, eu peço-lhes para fažerem uma reflexão, uma autoavaliação dessa aprendizagem. Durante o semestre há cinco momentos desta reflexão [...]. E, portanto, eu entrego uma fichinha com os objetivos de aprendizagem para ver como eles se posicionam no final da sequência de aulas. [...] Ponho mesmo os objetivos para aquelas aulas e perante isto eles vão-se posicionar: o que é que já domino, que dificuldades é que eu tenho e como é que eu me comprometo resolvê-las. (Professor A)

O professor B disse que a autoavaliação que os alunos fazem acontece, sobretudo, a partir de meados do semestre, no âmbito da realização do trabalho de grupo de elaboração de um projeto de investigação sobre um problema educativo. Essa autoavaliação é feita pelo questionamento aos elementos de cada grupo sobre se todos estão a participar de forma equitativa nesse trabalho, com o respetivo registro na grelha de observação do professor:

Ao fim de um mês e meio de aulas, eu vou fažer a auscultação. Vou pelos grupos e levo a ficha, vou pelos grupos e pergunto: meus meninos estamos aqui e a primeira pergunta que thes faço é se o trabalho estar a ser equitativo. Ouço-os sempre a eles, em que eles dizem quem é que acham que se pode distinguir pela positiva, que se pode destacar pela negativa, ou deve ser simplesmente retirado do grupo. [...] Eu escrevo aqui [grelha de observação]. (Professor B)

Esta autoavaliação não consiste num processo de reflexão, com base em critérios interiorizados, sobre a aprendizagem que estão a fazer, tal como sugere Allal (1999), restringindo-se à verbalização sobre a participação de cada aluno no trabalho que está a efetuar no seu grupo. Por essa razão, questionamos se se trata de uma autoavaliação como procedimento realizado para autorregulação e para a melhoria da aprendizagem de cada um.

Já o professor $C$ afirmou que as práticas de autoavaliação ocorrem no momento das reuniões de reflexão sobre as práticas de ensino dos estagiários, nas quais, com base nos critérios de avaliação das mesmas, os estagiários fazem uma avaliação descritiva sobre as suas aulas, identificando os aspetos positivos e as dificuldades sentidas. Desse modo, a autoavaliação possibilita uma reflexão sobre a aprendizagem, sendo facilitadora da utilização de estratégias de autorregulação das aprendizagens de cada estagiário (ALLAL, 1999; BÉLAIR, 2000). Porém essa reflexão culmina no posicionamento do desempenho do estagiário nas aulas num "perfil de desempenho", composto por comportamentos do estagiário no processo de ensino e que são definidos por níveis de uma escala qualitativa - "suficiente", "bom" e "muito bom"-, sendo estes do conhecimento dos estagiários.

Decorre dali [reunião de reflexão] uma conversa, é mesmo uma conversa entre alunos e professores, em que todos podemos dar opiniões fundamentadas e com base sempre nos critérios e em que se tenta que o aluno entenda as dificuldades que teve e que ele próprio 
também as expresse. [...] Avaliam a aula em função desses critérios e, de fato, é uma avaliação qualitativa. Fažem uma descritiva, em que eles fažem um texto que não têm que ler, mas que serve de base para eles falarem. Mas também têm espaço na mesma reflexão para eles se atribuirem as próprias opiniões se se situarem no perfil de bom, ou de muito bom, suficiente. (Professor C)

Esse professor referiu que essas práticas de autoavaliação também o ajudam na atribuição da classificação final na unidade curricular:

Aquilo que os alunos pensam é um indicador para nós, onde é que se enquadram, porque depois isso vai ser continuado. Há uma aula, depois outra e outra e eles vão-se enquadrando num perfil, que depois nos ajuda melhor a atribuir a nota final. (Professor C)

Tendo a avaliação formativa como principal função a regulação do processo de ensino e de aprendizagem (FERREIRA, 2007; HADJI, 2001), dois professores entrevistados relataram como procuram proceder à regulação desse processo. Assim, o professor A disse que a intervenção pedagógica nas dificuldades de aprendizagem é feita por ele por meio da revisão dos conteúdos não aprendidos pelos alunos, ou da leitura de textos suplementares que lhes disponibiliza. Também referiu que essa intervenção passa pela interajuda dos alunos, numa lógica de regulação interativa (ALLAL, 1999), em que aqueles que têm dificuldades solicitam a ajuda de colegas que não as têm:

[...] Talvez por pensarem: "se eu tenho esta dificuldade, ou o outro não a tem"... e vai procurar a ajuda com ele. Então eles interajudam-se. [...] Também a ajuda da professora, em que eu, normalmente, falo com eles e, às vezes, ponbo no SIDE textos de enriquecimento, dado que eles apresentaram dificuldade nessa matéria. (Professor A)

Já o professor $C$ mencionou a preocupação que tem em relação à correção atempada das planificações das aulas dos estagiários, de modo a dar-lhes o feedback de que precisam para alterarem o que não está adequado e, assim, poderem melhorar esses aspetos nas seguintes, tal como sugerem Ferreira (2007; 2011) e Leite e Fernandes (2002). Também referiu a importância dos comentários sobre as práticas de ensino dos estagiários nas reuniões de reflexão, como forma de os auxiliar a corrigir ou a melhorar a sua prática pedagógica nas aulas seguintes de sua responsabilização.

[Depois dos estagiários entregarem as planificações] Eu terei que combinar para corrigir hoje ainda, para amanhã estar com eles, porque depois vão ter uma nova planificação. Eu não gosto de deixar que eles façam uma nova planificação para a próxima aula sem eles terem o feedback, até para poderem alterar aquilo que não está bem.[...] [Decorrente da reflexão sobre a aula de cada estagiário] Depois tentamos, na semana seguinte, que esses aspetos sejam alterados e, normalmente, o sucesso do desempenho no estágio tem a ver com isso. A forma como eles vão integrando os comentários que vamos fazendo, vão alterando e melhorando. (Professor C) 
Apesar de os professores entrevistados procurarem realizar, o melhor possível, práticas de avaliação formativa que permitam identificar as aprendizagens que os alunos vão fazendo, a sua participação nos trabalhos e as dificuldades que vão sentindo, foram vários os obstáculos referidos para essa mesma prática. Obstáculos que, segundo eles, os impedem de acompanhar de forma mais sistemática e estruturada os processos de aprendizagem dos alunos, de lhes dar o feedback necessário e de intervir ou de negociar com eles essa intervenção de forma oportuna e adequada ante as dificuldades de aprendizagem. Aqueles mais referidos pelos professores foram o elevado número de alunos que têm, a diversidade de unidades curriculares que lecionam e, por isso, a falta de tempo para o acompanhamento, para a correcção atempada dos trabalhos que os alunos vão fazendo e para o respetivo feedback descritivo.

A questão é serem muitos alunos em muitas disciplinas. [...] Dar um feedback mais
em termos descritivos, isso não consigo, porque é muito trabalho que tenho e não consigo.
(Professor A)
Osprincipais obstáculos são o grande número de alunos que eu tenho e que os outros professores
têm, a dispersão de unidades curriculares. Tenho muitas unidades curriculares com uma hora,
uma hora e meia. Este tipo de trabalho precisa de mais tempo. (Professor B)

Há constrangimentos, claro que bá. O número de alunos torna mais difícil individualizar mais, acompanhar mais. Um número excessivo é sempre mau, não ajuda. Depois também o tempo, a questão do tempo, o estágio estar reduحido a um semestre [...], acho que é sempre curto, muito curto. (Professor C)

São muitos alunos por turma e tenho muitas unidades curriculares a lecionar, o que dificulta observar e acompanhar os alunos nas tarefas de aprendizagem e de avaliação que fazem. Por essa razão, é que eu não consigo dar o feedback necessário e sobretudo no tempo certo aos alunos, para que eles melhorem a sua aprendizagem e a sua prática de trabalho de projeto. (Professor D)

O relato desses obstáculos permite-nos compreender o fato de essas práticas avaliativas formativas não serem muito sistemáticas e estruturadas. Também Perrenoud (1993) refere que a prática da avaliação formativa pressupõe enfrentar diversos obstáculos de natureza organizacional, pedagógica e prática dos docentes e dos próprios alunos. Por essas razões, os formadores têm consciência daquilo que consideram ser preciso melhorar na avaliação das aprendizagens dos futuros professores. O professor A afirmou que, se tivesse mais tempo e menos alunos, teria mais condições para dar um feedback descritivo mais frequente aos alunos sobre os seus resultados nos testes de avaliação sumativa, de modo que vissem o que responderam bem e o que erraram. 
[Melhorava o feedback] talvez. [n] os testes de avaliação sumativa, porque, mesmo assim, en levo sempre para a aula, para eles verem. Mas aí, en acho que poderia fazer um trabalho mais cuidado, porque poderia dar esse feedback. (Professor A)

O professor B mencionou também a necessidade de ter mais tempo para aperfeiçoar a sua prática de avaliação da aprendizagem, no sentido de corrigir continuamente o que os alunos vão fazendo nos trabalhos das aulas práticas e, dessa forma, de poder dar mais feedback aos futuros professores durante a realização desses trabalhos, acompanhando-os mais.

Era mais ou menos isto que estou a fažer mas com mais tempo, com mais atenção, mais aperfeiçoado, dar-lhes mais acompanhamento, poder dar mais feedback. [...] O ideal era levar para casa [o trabalho semanal de cada grupo], corrigir e dar o feedback, mas não dá. (Professor B)

O professor $\mathrm{C}$ referiu a necessidade de melhorar os critérios de avaliação das aulas lecionadas pelos estagiários e de contemplar a auto e a heteroavaliação na avaliação sumativa, dizendo não o fazer pelo fato de os futuros professores não serem sempre justos na apreciação e no seu posicionamento segundo o "perfil de desempenho" que serve para a classificação das aulas por eles lecionadas.

Claro que, como en disse, eu penso que tudo isto posso sempre melhorar. [...] Olho para trás e digo: "não, acho que tenho que melhorar aquele instrumento, aquele critério". [...] Continuo a dizer que gostava muito de contemplar na prática a auto e a heteroavaliação como ponderação. Acho que deveria ter uma ponderação na classificação final e não tenho por estas dúvidas que eu já falei. Eu acho que aí os alunos não são muito verdadeiros, a maioria deles. (Professor C)

Apesar de os professores entrevistados tentarem praticar a avaliação formativa, mesmo com os obstáculos sentidos e que constituem, segundo eles, verdadeiras limitações a essa prática, a avaliação sumativa é aquela que se encontra mais estruturada e que é realizada de uma forma mais planeada, fruto da tradição dessa avaliação como medida no Ensino Superior e das exigências institucionais (FERNANDES, 2010). Assim, os professores identificaram os instrumentos de avaliação sumativa que utilizam para classificar os alunos e o peso que cada um deles tem nessa classificação final, sendo alguns deles aqueles que procuram acompanhar no contexto da avaliação formativa.

Durante o semestre há cinco momentos de reflexão e eles sabem que cada momento de reflexão vale $2 \%$ desses $10 \%$ [que vale a autoavaliação na classificação final]. Depois, também é um trabalho em grupo e esse trabalho em grupo tem uma componente comum e uma componente individualizada. A parte escrita do trabalbo é a componente em 
grupo e depois eles têm uma componente individualizada com a apresentação na aula do trabalho. [...] Eles depois fazem um teste, que é uma avaliação individual, que é um teste sumativo no final do semestre. (Professor A)

Este ano eles escolhem um tópico da revisão da literatura, porque eles não vão fazuer um projeto [de investigação]. Eles vão faz̧er um pré-projeto, que é um trabalbo de grupo muito simples, poucas páginas e, portanto, têm que fazer um pré-projeto sobre um tema à escolha e em cada item do pré-projeto eles têm que justificar esse item. [...] Depois, há uma componente individual, que é uma coisa muito pequenina, que é a conclusão. (Professor B)

As planificações, a autoavaliação dos alunos, o relatório de caracterização, o documento do projeto e o relatório do projeto e as responsabilizações. A responsabilização é o que tem mais ponderação no estágio. Tem 12, os outros têm 2 na planificação, 5 os relatórios. (Professor C)

Como a unidade curricular é sobre a metodologia de trabalho de projeto, eles fazem um documento do projeto que conta $25 \%$ na classificação final, mais $25 \%$ das planificações semanais do desenvolvimento do projeto nas escolas do $1^{\circ}$ ciclo e $50 \%$ o relatório final do desenvolvimento do projeto. (Professor D)

Desses relatos dos professores verifica-se a utilização privilegiada de trabalhos de natureza diversa na avaliação sumativa dos futuros professores em cada unidade curricular, trabalhos estes que procuram incidir sobre problemas ou funções da vida profissional que esses futuros professores irão exercer e que, pretensamente, thes possibilitarão aprender conhecimentos e desenvolver competências necessárias ao exercício da profissão. Desse modo, a prática avaliativa procura aproximar-se da avaliação de competências profissionais dos futuros professores, na medida em que esses trabalhos os conduzem a analisar as situações, a tomar decisões em grupo, mobilizando saberes diversos e procedimentos distintos (PACHECO, 2011; CLARES; JUAREZ; CANTERO, 2008; VALVERDE; REVUELTA; FERNANDÉZ, 2012).

\section{CONSIDERAÇÕES FINAIS}

Se, atualmente, a formação inicial de professores portuguesa se encontra a viver profundas mudanças pedagógicas, as práticas de avaliação das aprendizagens realizadas pelos docentes do Ensino Superior não podem permanecer indiferentes. No contexto de Bolonha e da sociedade do conhecimento, que está em constante mudança, em que se integra a realidade educativa complexa na qual os futuros professores do $1^{\circ}$ ciclo do ensino básico irão lecionar, são fundamentais a aquisição e o desenvolvimento de competências profissionais, pessoais e sociais por meio do estudo e do trabalho autônomos desses estudantes, sob a supervisão e a orientação dos docentes. Desse modo, as práticas avaliativas têm que se adequar a esses novos objetos e intervenientes na avaliação das aprendizagens. 
Assim, o estudo realizado até o momento - e que se encontra em fase de desenvolvimento - sobre a avaliação das aprendizagens na formação inicial de professores do $1^{\circ}$ ciclo do ensino básico da Universidade de Trás-os-Montes e Alto Douro permite-nos concluir que as palavras dos docentes entrevistados evidenciam uma mudança de concepção e de práticas de avaliação das aprendizagens. Segundo eles, essa avaliação não consiste só em classificar os alunos em cada unidade curricular segundo a medição de conhecimentos em testes e exames, mas inclui também uma dimensão formativa, a qual, apesar de não assumir ainda grande estruturação e sistematicidade, é concretizada pela tentativa de acompanhamento e feedback aos alunos na realização de tarefas decididas pelos professores no âmbito das respetivas unidades curriculares e que servirão para a sua classificação no âmbito da avaliação sumativa. De acordo com essa perspectiva, as tarefas visam preparar os futuros professores para as atividades profissionais que irão realizar, pressupondo-se a mobilização, por parte deles, de conhecimentos e de procedimentos diversos do domínio profissional e social. A avaliação formativa também é concretizada pela preocupação em levar os futuros professores a participarem na apreciação das suas aprendizagens, mediante autoavaliação. Porém essa autoavaliação é, também, pouco estruturada e pouco sistemática e não tem tido, de acordo com os discursos dos entrevistados, quaisquer efeitos de autorregulação da aprendizagem pelos futuros professores.

A prática de avaliação formativa analisada, por todas essas razões, precisa ser melhorada, estruturada e orientada para uma maior participação dos estudantes na avaliação do seu processo de aprendizagem de conhecimentos e de competências, criando-se as condições pedagógicas necessárias para estudo e trabalho autônomos dos futuros professores. Contudo, essa melhoria está dependente de obstáculos sentidos pelos docentes à realização de uma prática de avaliação formativa e formadora, como o elevado número de alunos e de unidades curriculares que têm a seu cargo, mas também devido à falta de hábitos ante uma cultura avaliativa em que a avaliação é feita para auxiliar os alunos a aprenderem.

\section{REFERÊNCIAS}

AFONSO, Almerindo Janela. Questões polémicas no debate sobre políticas educativas contemporâneas: o caso da accountability baseada em testes estandardizados e rankings escolares. In: ALVES, Maria Palmira; DE KETELE, Jean-Marie (Orgs.). Do currículo à avaliação, da avaliação ao currículo. Porto: Porto Editora, 2011, p. 83-101.

ALLAL, Linda. Impliquerl'apprenantdansle processos d'évaluation: promessesetpièges de l'autoévaluation. In: DEPOVER, Christian; NÖEL, Bernardette (Eds.). L'évaluation 
des competences et desprocessus cognitifs. Modèles, pratiques et contexts. Bruxelles: De Boeck Université, 1999, p. 35-56.

ALONSO, Luiza. Questões críticas acerca da construção de um currículo formativo integrado. In: SIMPÓSIO NACIONAL DE EDUCAÇÃO PRÉ-ESCOLAR E PRIMEIRO CICLO. Formação de Professores e Educadores de Infância. Questões do Presente e Perspectivas Futuras, 1., 2005, Universidade de Aveiro. Actas... Aveiro: Universidade de Aveiro, 2005, p. 1-17.

ALVES, Maria Palmira. Currículo e Avaliação. Porto: Porto Editora, 2004. 141p.

BARDIN, Laurence. Análise de conteúdo. Lisboa: Edições 70, 1995, 225p.

BÉLAIR, Louise M. La evaluaciónen la acción: el dossier progressivo de los alumnos. Sevilha: Díada Editora, 2000. 96p.

BOGDAN, Robert; BIKLEN, Sari. Investigação qualitativa em educação. Porto: Porto Editora, 1994. 335p.

CLARES, Pilar Martínez; JUÁREZ, MirianMartínez; CANTERO, Jesús Miguel Nuñez. Aprendizaje de Competenciasen Educación Superior. Revista Galego-Portuguesa de Psicoloxía e Educación. A Coruña, v. 16 (1,2), p. 195-215, 2008.

CORTESÃO, Luiza. Formas de ensinar, formas de avaliar. Breve análise de práticas correntes de avaliação. In: ABRANTES, Paulo; ARAÚJO, Filomena (Coord.). Reorganização Curricular do Ensino Básico. Avaliação das Aprendizagens. Das concepções às práticas. Lisboa: Ministério da Educação, Departamento da Educação Básica, 2002, p. 37-42.

DECLARAÇÃO DE BOLONHA. 1999. In: SERRALHEIRO, José Paulo (Org.). O Processo de Bolonha e a formação dos educadores e professores portugueses. Porto: Profedições / Jornal a Página, 2005, p. 171-174.

ESTEVES, Manuela. Análise de Conteúdo. In: LIMA, Jorge Ávila de; PACHECO, José Augusto (Orgs.). Faz̧er investigação: contributos para a elaboração de dissertações e teses. Porto: Porto Editora, 2006, p. 105-126.

. Para a excelência pedagógica do ensino superior. Sísifo - Revista de Ciências da Educação, v. 7, p. 101-110, 2008.

FIGARI, Gérard. Avaliar: que referencial? Porto: Porto Editora, 1996. 189p.

FERNANDES, Preciosa. A avaliação da aprendizagem no ensino superior. Possibilidades e limites de uma prática formativa/avaliativa. In: LEITE, Carlinda (Org.). Sentidos da pedagogia no ensino superior. Porto: CIIE/Livpsic, 2010, p. 99-110.

FERREIRA, Carlos Alberto. A avaliação no quotidiano da sala de aula. Porto: Porto Editora, 2007. 238p.

. O feedback na avaliação reguladora da aprendizagem: reflexões para a prática. In: CONGRESO INTERNACIONAL GALEGO-PORTUGUÉS DE PSICOPEDAGOXIA, 11., 2011, Universidade de Coruña. Libro de Actas... La Coruña: Universidade de Coruña, 2011, p. 341-349.

FIGARI, Gérard. Avaliar: que referencial?. Porto: Porto Editora, 1996, 189p.

GHIGLIONE, Rodolphe; MATALON, Benjamim. O Inquérito: teoria e prática. Oeiras: Celta Editora, 1992. 370p.

HADJI, Charles. Avaliação desmistificada. Tradução de Patrícia C. Ramos. Porto Alegre: Artmed Editora, 2001. 136p.

LEBRUN, Marcel. Teorias e métodos pedagógicos para ensinar e aprender. Lisboa: Instituto Piaget, 2008. 240p. 
LEITE, Carlinda; FERNANDES, Preciosa. A avaliação das aprendizagens dos alunos: novos contextos, novas práticas. Porto: Edições Asa, 2002. 84p.

LIMA, Licínio; AZEVEDO, Mário; CATANI, Afrânio. O Processo de Bolonha, a avaliação da educação superior e algumas considerações sobre a Universidade Nova. Avaliação. Revista de Avaliação da Educaşão Superior, v. 13, n. 1, p. 7-36, 2008.

LIMA, Jorge Ávila de. Ética na Investigação. In: LIMA, Jorge Ávila de; PACHECO, José Augusto (Orgs.). Faz̧er investigação: contributos para a elaboração de dissertações e teses. Porto: Porto Editora, 2006, p. 127-159.

MORGADO, José Carlos. O Processo de Bolonha e Ensino Superior num mundo globalizado. Revista Educação \& Sociedade, v. 30, n. 106, p. 37-62, 2009.

PACHECO, José Augusto. Políticas educativas para o Ensino Superior na União Europeia: um olhar do lado português. Revista Educação \& Sociedade, v. 24, n. 82, p. 17-36, 2003.

Discursos e lugares das competências em contextos de educação e formação. Porto: Porto Editora, 2011. 128p.

PASTOR, Víctor M. López. Evaluación Formativa y Compartida en Educación Superior: propuestas, técnicas, instrumentos y experiencias. 2. ed. Madrid: Narcea Ediciones, 2011. 270p.

PERRENOUD, Philippe. Não mexam na minha avaliação! Para uma abordagem sistémica da mudança pedagógica. In: ESTRELA, Albano; NÓVOA, António (Org.). Avaliações em Educação: Novas Perspectivas. Porto: Porto Editora, 1993, p. 171-191.

. L'évaluation des élèves. De la fabrication de l'excellence à la régulation des apprentissages. Entre deux logiques. Bruxelles: De Boeck Université, 1998. 219p.

Dez novas competências para ensinar. Tradução de Patrícia Chittoni Ramos. Porto Alegre: Artmed Editora, 2000. 192p.

ROLDÃO, Maria do Céu. Educação Básica e Currículo: Perspectivas para a sociedade do $3^{\circ}$ milénio. In: DUARTE, José B. (Org.). Igualdade e diferença numa escola para todos. Lisboa: Edições Universitárias Lusófonas, 2002, p. 45-64.

ROSALES, Carlos. Avaliar é reflectir sobre o ensino. Porto: Edições Asa, 1992. 264p.

SANTAMARIA, José Sánchez. Evaluación de los aprendizajes universitários: una comparación sobre sus possibilidades y limitacionesen el Espacio Europeo de Educación Superior. Revista de Formación e Innovación Educativa Universitária, v. 4, n. 1, p. 40-54, 2011.

SECO, Graça et al. Promoção de competências transversais no Ensino Superior. In: CONGRESO INTERNACIONAL GALEGO-PORTUGUÉS DE PSICOPEDAGOXÍA, 11., 2011, Universidade de Coruña. Libro de Actas... La Coruña: Universidade da Coruña, 2011.p. 809- 819. SIMÃO, José Veiga; SANTOS, Sérgio Machado; COSTA, António de Almeida. Ambição para a excelência: a oportunidade de bolonha. Lisboa: Gradiva, 2005. 302p.

VALVERDE, Jesús; REVUELTA, Francisco Ignacio; FERNANDÉZ, María Rosa. Modelos de evaluación por competenciasa través de un sistema de gestión de aprendizaje. Experiencias en la formación inicial del profesorado. Revista Iberoamericana de Educación, n. 60 , p. 51-62, 2012.

\section{NOTAS}

${ }^{1}$ À frente é feita uma breve caracterização do processo de Bolonha.

${ }^{2}$ Estamos a referir-nos à formação de professores que lecionam nos primeiros quatro anos de escolaridade do ensino básico português. 
Recebido: 16/04/2013

Aprovado: 01/06/2015

Contato:

Universidade de Tras-os-Montes e Alto Douro Escola de Ciências Humanas e Sociais Quinta de Prados Vila Real | Portugal 5000-801 
